\title{
Os conceitos científicos dos estudantes do Ensino Médio no estudo do tema "origem da vida"
}

\author{
Scientific concepts of high school students \\ on the topic of study "the origin of life"
}

Camila Grimes $^{1}$ • Edson Schroeder ${ }^{1}$

\begin{abstract}
Resumo: A pesquisa teve como objetivo compreender, a partir de conceitos espontâneos, os processos de construção de conceitos científicos, pelos estudantes em aulas de Biologia, no estudo do tema "origem da vida". Participaram do estudo 45 estudantes do Ensino Médio, de uma escola pública em Blumenau, Santa Catarina, Brasil. Como instrumentos de coleta de dados, utilizamos a videogravação das aulas, entrevistas semiestruturadas e a Atividade de Construção e de Complemento. Os dados foram analisados a partir da matriz histórico-cultural - análise microgenética. Como resultados, foi possível perceber que o ensino e a aprendizagem da temática em sala de aula se caracterizam como de extrema complexidade, visto que aspectos culturais e afetivos estão envolvidos na construção dos conceitos científicos. Podemos observar que alguns estudantes apresentaram conceitos, especialmente após o processo de ensino, ancorados no conhecimento científico estudado no decorrer das aulas, superando seus conceitos mais primitivos.
\end{abstract}

Palavras-chave: Teoria histórico-cultural. Conceitos. Ensino e aprendizagem. Ensino de biologia. Ensino Médio.

\begin{abstract}
The research aimed to understand, from spontaneous responses, the processes of the construction of scientific concepts by students in biology classes, when dealing with the topic "The Origin of Life". The participants were 45 public high school students in Blumenau, Santa Catarina, Brazil. As instruments of data collection, we used video recording of classes together with semi-structured interviews and a Construction and Complement Activity. We analyzed the data through a Historical and Cultural matrix - a microgenetic analysis. As a result, we noticed that we could characterize the teaching and learning of the subject in the classroom as extremely complex, since cultural and affective aspects are involved in the construction of scientific concepts. We could also observe that some students, especially after the teaching process, presented concepts grounded in the scientific studied done during the classes, outperforming their earlier concepts.
\end{abstract}

Keywords: Historical and cultural theory. Concepts. Teaching and learning. Biology teaching. High School.

\footnotetext{
${ }^{1}$ Universidade Regional de Blumenau (FURB), Campus I, sala I-202, Rua Antônio da Veiga, 140, Victor Konder, Blumenau, SC, Brasil. E-mail: <professora.camilagrimes@gmail.com>
} 


\section{Introdução}

A aprendizagem, para Vygotsky, trata-se de um movimento constante e não linear, pois os indivíduos se encontram em um intenso processo de construção dos significados culturais (OLIVEIRA, 2002). O desenvolvimento do pensamento é influenciado diretamente pelos signos, pelas experiências socioculturais de cada indivíduo e pelo domínio da linguagem (VYGOTSKY, 2001). Nessa perspectiva, Vygotsky (1998a) argumenta que a origem das formas humanas de inteligência emerge na convergência das dimensões elementares ou biológicas e das dimensões superiores, processo que se dá por meio das relações sociais de produção. Complementando essa revisão, o autor infere que o aprendizado vai além do desenvolvimento da capacidade de pensar, pois possibilita o desenvolvimento de várias capacidades individualizadas em raciocinar sobre diversos aspectos. Desse modo, a mente humana não se constitui de capacidades gerais, mas um conjunto de capacidades específicas independentes. Rego (2000) evidencia, ainda, que o aprendizado proporciona o desenvolvimento de competências psicológicas específicas do ser humano, já estabelecidas por meio da sua cultura. No processo de aprendizagem, a construção de conceitos tem um papel fundamental.

$\mathrm{Na}$ aprendizagem, a dialética proporciona o processo de internalização das funções psicológicas superiores, no desenvolvimento do pensamento conceitual. Vygotsky (1998a, p. 75) realiza importante discussão sobre o processo de internalização do conhecimento:

Um processo interpessoal é transformado num processo intrapessoal. Todas as funções no desenvolvimento da criança aparecem duas vezes: primeiro, no nível social, e, depois, no nível individual; primeiro, entre pessoas (interpsicológica), e, depois, no interior da criança (intrapsicológica). Isso se aplica igualmente para a atenção voluntária, para a memória lógica e para a formação de conceitos. Todas as funções superiores originam-se das relações reais entre indivíduos humanos.

No ambiente escolar, os processos de internalização acontecem na Zona de Desenvolvimento Proximal - ZDP. Nesta a aprendizagem desencadeia o desenvolvimento de processos internos dos estudantes, pois, além de se considerar o patamar atingido, levam-se em consideração as capacidades que se encontram em estágio de maturação. Ou seja, o patamar que os estudantes podem atingir com o auxílio do outro, quando ocorrem as relações sociais e cooperação entre os indivíduos. A partir do momento que o conhecimento for internalizado pelos estudantes, passam a fazer parte do desenvolvimento específico de cada indivíduo (VYGOTSKY, 1998a).

Vygotsky (1998a) ressalta que as aprendizagens, antes do ingresso do estudante no ambiente escolar, diferem das aprendizagens que decorrem do período escolar. Segundo Rego (2000), a escola proporciona, aos estudantes, o acesso a um conjunto de conhecimentos sistemáticos, que se refere a aspectos muito mais complexos sobre sua realidade, conhecimentos construídos e acumulados pela humanidade (conceitos científicos). Sua aprendizagem permite que se conscientizem do seu próprio processo mental (VYGOTSKY, 2001). Os conceitos científicos não possuem todas as características do pensamento infantil, em cada nível do seu desenvolvimento, pois esses conceitos não são internalizados mecanicamente, mas sim, a partir de uma intensa atividade cognitiva dos estudantes. O aprendizado dos conhecimentos cien- 
tíficos, de um determinado conceito, possibilita o desenvolvimento das funções psicológicas superiores e transcende os limites desse conteúdo, pois as funções psicológicas envolvidas na aprendizagem dos mais variados conceitos possuem correlação, tendo como alicerce a consciência e o domínio deliberado, aspectos psicológicos que se dão em um longo processo escolar (VYGOTSKY, 1998b).

O desenvolvimento das funções psicológicas superiores, no processo de formação do pensamento conceitual, não ocorre de forma mecânica e gradual, do concreto para o abstrato, e sim, da transformação complexa e dinâmica, na estrutura, na base do pensamento dos indivíduos (VYGOTSKY, 2001). Para Vygotsky (1998b), a formação de conceitos perpassa por três etapas básicas: o pensamento sincrético, o pensamento por complexo e o pensamento conceitual propriamente dito.

Segundo o autor, o pensamento sincrético acontece no início do desenvolvimento infantil e, nesta etapa do desenvolvimento, a criança já utiliza nexos objetivos (já ocorre a formação de categorias conceituais, muito embora ainda não reflitam o conceito propriamente dito). Entretanto, muitas destas categorias, de fato, não têm relação com o conceito (excesso de conexões e debilidade de abstração). Cria-se a base para generalizações posteriores mais sofisticadas. No pensamento por complexos, os objetos se conectam na mente da criança, devido às impressões pessoais e as relações entre os objetos, pois, nessa etapa, as crianças encontram-se mais maduras e diferenciam as impressões individuais da relação entre as coisas. O pensamento por complexo caracteriza-se como: coerente, objetivo, concreto e factual, entretanto, não ainda tão objetivo e abstrato quanto o pensamento conceitual.

Por fim, para o autor, no pensamento conceitual, além da unificação das impressões, realizam-se a abstração e o isolamento de componentes, analisam-se os componentes abstratos separadamente do contexto. A formação de conceito ocorre somente com a apropriação da abstração, bem como do pensamento por complexo em sua totalidade. Nesta etapa, o conceito se torna instrumento do pensamento e possibilita: a generalização, a discriminação, a abstração, o isolamento, a decomposição, a análise e a síntese, implicando o desenvolvimento das funções psíquicas superiores. Segundo Vygotsky (1998b, p. 66-67), “[...] um conceito não é uma formação isolada, fossilizada e imutável, mas sim uma parte ativa do processo intelectual, constantemente a serviço da comunicação, do entendimento e da solução de problemas". Para o autor, a formação de conceitos é desencadeada no início da infância, contudo, as funções psicológicas, geradas nesse processo, amadurecem e se desenvolvem apenas na adolescência. Antes da adolescência, os indivíduos possuem funções intelectuais que se assemelham à formação de conceitos verdadeiros.

Segundo o autor, a construção de conceitos ocorre por meio da operação intelectual, mediada pela palavra, que possibilita ativar a atenção, suprimir elementos e sintetizá-los através de um signo, podendo resultar, assim, no desenvolvimento das funções mentais. O desenvolvimento dos conceitos não espontâneos ou científicos não difere do desenvolvimento dos conceitos cotidianos ou espontâneos dos estudantes, porque os dois processos se relacionam, se influenciam e se movimentam, uniformemente, participando de um único procedimento, o da construção conceitual.

Vygotsky (1998b, p. 136) infere, ainda, sobre a construção e a relação entre conceitos espontâneos e científicos: 
Ao forçar a sua lenta trajetória para cima, um conceito cotidiano abre caminho para um conceito científico e o seu desenvolvimento descende. Cria uma série de estruturas necessárias para a evolução dos aspectos mais primitivos e elementares de um conceito, que lhe dão corpo e vitalidade. Os conceitos científicos, por sua vez, fornecem estruturas para o desenvolvimento ascendente dos conceitos espontâneos da criança em relação a consciência e ao uso deliberado. Os conceitos científicos desenvolvem-se para baixo por meio dos conceitos espontâneos; os conceitos espontâneos se desenvolvem para cima por meio dos conceitos científicos.

Complementando esse pensamento, Vygotsky (1998b) enfatiza que, na formação de conceito no ambiente escolar, a relação dos estudantes com o conhecimento científico pode ser mediada pelo professor, desde o primeiro momento, com o conhecimento espontâneo. Assim, a aprendizagem dos conceitos científicos tem como alicerce os conceitos espontâneos, dentro de um sistema conceitual. De tal modo, ressaltamos a importância e o pioneirismo do pensamento vygotskyano para a área educacional, especificamente para o ensino de Ciências Naturais, no que diz respeito ao entendimento dos processos de construção do conhecimento, dos conceitos científicos. Assim sendo, justificamos a opção pela teoria histórico-cultural de Lev Semionovitch Vygotsky como referencial teórico dessa pesquisa.

O ensino de Biologia no Ensino Médio reveste-se de grande importância, pois abre espaço para o desenvolvimento da educação científica, pois, para Cachapuz et al. (2005, p. 17), este tipo de educação tem como prioridade o desenvolvimento da sociedade, sendo que seu objetivo social consiste "tanto para a preparação de futuros científicos, como para a formação de cidadãos susceptíveis de participar na tomada fundamentada de decisões em torno de problemas sócio-científicos e sócio-tecnológicos cada vez mais complexos”. Os autores destacam, ainda, que, para a tomada de decisões dos indivíduos, a alfabetização científica, bem como uma educação científica e tecnológica de qualidade, é fundamental para todos, resultando, assim, no desenvolvimento pessoal, tanto em curto como em longo prazo. Delizoicov, Angotti e Pernambuco (2002) discutem, também, que o ensino de Ciências Naturais tem como função permitir ao estudante se apropriar da estrutura do conhecimento científico e de seu potencial explicativo e transformador.

A temática "origem da vida" faz parte dos conteúdos curriculares de Ciências Naturais, contudo, possui grande carga de conhecimentos espontâneos, devido à cultura e a religião. Investigações apontam uma problemática no ensino e na aprendizagem do tema "origem da vida", assim como forte influência da religião sobre a temática, na visão de estudantes e professores (CERQUEIRA, 2009; NICOLINI, 2006; SANTOS, 2007). Diante do exposto, estabelecemos como objetivo geral, compreender, a partir de conceitos espontâneos, os processos de construção de conceitos científicos pelos estudantes, por meio de um processo de ensino e de aprendizagem sobre o tema "origem da vida". 


\section{Metodologia}

Como cenário de investigação, temos uma turma com 45 estudantes adolescentes cursando a primeira série do Ensino Médio, no período noturno, e seu professor de Biologia, em uma escola pública da Rede Estadual de Ensino de Blumenau, Santa Catarina, Brasil, no desenvolvimento do tema "origem da vida".

Como instrumentos de coleta de dados, utilizamos: videogravação das aulas, entrevistas semiestruturadas com os sujeitos e a atividade de construção e de complemento. A videogravação e a atividade de transcrição detalhada estão associadas aos estudos socioculturais, com base na teoria histórico-cultural (GÓES, 2000). Desse modo, filmamos todas as aulas referente à temática "origem da vida", sendo que, posteriormente, os vídeos foram transcritos. O processo de ensino investigado durou quase dois meses, tendo início no dia 27 de fevereiro e término no dia 16 de abril de 2012, totalizando 16 aulas-hora observadas. As entrevistas semiestruturadas individuais foram utilizadas como instrumento de coleta de dados, efetivadas com o professor e os estudantes. As entrevistas facilitaram a compreensão do processo de construção conceitual, visto que foram realizadas após o término das aulas sobre a temática pesquisada. Segundo Bauer e Gaskell (2008), a entrevista semiestruturada individual trata-se de uma metodologia de coleta de dados, utilizada de forma recorrente em investigações qualitativas, uma vez que fornece dados para a compreensão das relações entre os atores sociais e a sua situação, ou seja, objetiva a compreensão minuciosa das crenças, atitudes, valores, dentre outros, relacionados a comportamentos dos indivíduos, em determinados contextos sociais.

A atividade de construção e de complemento também foi utilizada como instrumento de coleta de dados, teve como estímulos figuras com legendas das hipóteses sobre a origem da vida, criacionismo, abiogênese, panspermia e evolução química, bem como a frase de comando "Agora é com você. Na sua visão a vida se originou...". Nosso intuito foi motivar os estudantes a dissertarem sobre o tema de investigação, por meio desses estímulos. Nesse sentido, Vergara (2006) ressalta que as atividades de complemento são instrumentos para a coleta de dados, nos quais o pesquisador apresenta, ao respondente, um estímulo, como, por exemplo, uma frase de comando, para ser preenchido e desenvolvido com palavras. Espera-se a revelação de concepções e suas crenças subjacentes, motivações e sentimentos, que dificilmente seriam captados por outros instrumentos convencionais. Já as atividades de construção, geralmente, utilizam fotografias ou figuras para estimular a imaginação dos sujeitos, fazendo com que as interpretem e realizem uma narrativa relacionada ao tema da pesquisa. Todos os estudantes participaram dessa atividade em duas etapas. Na primeira, aconteceu a aplicação da atividade antes de o professor abordar o conteúdo relacionado ao tema, para identificar os conceitos espontâneos (nível de desenvolvimento potencial). Já na segunda etapa, a mesma atividade foi aplicada novamente, para identificar as concepções dos estudantes após o processo de ensino (nível de desenvolvimento real).

No processo de ensino, procuramos compreender a dinâmica do ambiente histórico e cultural, assim como, a mediação do Professor no processo de desenvolvimento cognitivo dos estudantes. Para Wertsch, Del Rio e Alvarez (1998), a investigação sociocultural tem como objetivo compreender a mente humana e a sua relação com o contexto, ou seja, a relação entre o indivíduo e a sociedade. Na presente investigação, optamos pela análise microgenética como abordagem metodológica. De acordo com Góes (2000), a análise microgenética é utilizada nas 
investigações sobre a constituição dos sujeitos, sobretudo em contextos educativos, uma vez que consiste numa forma de construção de dados, focada nos detalhes e no recorte de episódios interativos nas interações sociais de produção. Para Vygotsky (2001), um corpo só mostra o que é quando se encontra em movimento.

A análise microgenética apoia-se na matriz histórico-cultural, e tem como objetivo compreender os sujeitos e suas relações intersubjetivas, em contex tos históricos e culturais, resultando na compreensão minuciosa dos acontecimentos. Góes (2000, p.11) argumenta, ainda, que:

À primeira vista, nota-se uma proximidade da análise microetnográfica com a microgenética, pois esta última está igualmente orientada para os detalhes das ações; para as interações e cenários socioculturais; para o estabelecimento de relações entre microeventos e condições macrossociais. Por outro lado, uma primeira característica distintiva pode ser identificada, não no termo micro em si, mas na sua qualificação como genética, o que parece estabelecer um contraste com o aporte etnográfico. A visão genética aí implicada vem das proposições de Vygotsky (1981, 1987a) sobre o funcionamento humano, e, dentre as diretrizes metodológicas que ele explorou, estava incluída a análise minuciosa de um processo, de modo a configurar sua gênese social e as transformações do curso de eventos.

Andrade e Smolka (2009) enfatizam, também, que, na análise microgenética, Vygotsky propõe o estudo: da natureza, da gênese, dos processos biológicos, ontológicos e sociais, suas relações, evoluções e transformações, resultando no desenvolvimento das funções psicológicas superiores, para, dessa maneira, compreender o comportamento do ser humano.

A escola e todos os sujeitos envolvidos na investigação possuem sua identidade preservada e, nesse sentido, atribuímos uma numeração específica para cada estudante, de forma aleatória, e referimo-nos, ao docente, como Professor. Em todas as produções escolares, a escrita original dos estudantes foi mantida.

Neste artigo, apresentamos o recorte a partir de um estudo que deu origem a uma dissertação de Mestrado intitulada $A$ construção de conceitos científicos no estudo do tema origem da vida (GRIMES, 2013).

\section{Resultados e discussão}

Nas aulas investigadas, o Professor mediou a aprendizagem dos conceitos científicos relacionados ao método científico, origem do universo, hipóteses da origem da vida (criacionismo, abiogênese, panspermia e evolução química) e evolução dos seres vivos; contudo, nesta pesquisa, analisamos somente a construção de conceitos sobre a origem da vida. Como ferramentas de ensino, o professor utilizou: documentários, textos, livro didático e slides. $\mathrm{Na}$ avaliação da aprendizagem, os estudantes elaboraram textos e desenvolveram seminários sobre a temática de estudo. 
O professor apresentou as quatro hipóteses explicativas sobre a origem da vida, diferenciando-as de maneira superficial. Além disto, atribuiu pouca importância ao papel educativo dos conceitos espontâneos dos estudantes e as relações sociais de produção em sala de aula, pois não questionava os estudantes, suas vivências, suas opiniões, exceto uma única vez. Nesta aula, solicitou que conversassem em grupos sobre as hipóteses da origem da vida e, após, ocorreu a socialização dos debates com a classe. Contudo, no momento de apresentação, somente questionou os estudantes se houve conflito nas concepções do grupo, mas solicitou que não falassem qual conflito havia ocorrido.

Esse cenário com pouca interação social, com configuração tradicional, pode dificultar a construção do conhecimento. E esse bloqueio do professor em discutir esse tema controverso, também pode ter influenciado nos processos de construção conceitual. Ressaltamos que não é função das aulas de Biologia discutir religião, entretanto, na perspectiva histórico-cultural, para que ocorra a construção dos conceitos científicos em sala se aula, faz-se necessário que o docente dialogue com os estudantes a respeito dos seus conceitos espontâneos, para proporcionar a introdução do conhecimento científico, tornando esse, significativo para os estudantes.

Durante as aulas, nos processos de construção de conceitos científicos, podemos perceber que os estudantes desenvolvem o pensamento conceitual em níveis e complexidades distintas, visto que a base para a construção dos conceitos científicos são os conceitos espontâneos, sendo assim, cada estudante possui uma realidade sociocultural distinta, resultando em um processo de construção conceitual individual. Dessa forma, sobre a construção de conceitos científicos no estudo do tema "origem da vida", tendo como apoio as análises das videogravações, as atividades de construção e de complemento, além das entrevistas realizadas com os estudantes e o professor, identificamos três estágios principais de pensamento conceitual sobre a temática e diversas variações em cada estágio. Sendo eles: (1) estudantes que não transformaram os seus conceitos relacionados à origem da vida; (2) estudantes que atribuem a origem da vida ao criacionismo, mas ainda possuem dúvidas; e (3) estudantes que transformaram os seus conceitos relacionados à origem da vida.

De tal modo, analisamos o primeiro estágio de pensamento conceitual que consiste em "Estudantes que não transformaram os seus conceitos relacionados à origem da vida". Muitos estudantes, apesar do processo de ensino, permaneceram com os seus conceitos espontâneos, defendendo a ideia criacionista como possibilidade explicativa, conforme comparação a seguir.

Conceitos de um estudante relacionados à origem da vida, antes do processo de ensino - Nível de Desenvolvimento Potencial:

Para mim a vida se formo [criou] quando Deus construi o mundo, Talvez seja só teoria de que ele deixou na terra uma fêmea e um macho de cada animal. Depois veio se ser humano se modificando até chegar no que somos hoje. [Estudante 31]

Após o processo de ensino - Nível de Desenvolvimento Real:

Apesar de ter estudados outras teorias que podem ser verdade, para mim, o mundo foi criado de um ser superior. [Estudante 31]. [atividade de construção e de complemento] 
Conforme Vygotsky (1998a), o aprendizado dos estudantes começa muito antes do ambiente escolar; há sempre uma história prévia. Evidentemente, os estudantes possuem uma bagagem de conhecimentos relacionados à origem da vida, antes do contato com os conteúdos científicos relacionados ao tema, no ambiente escolar. Na verdade, trata-se de um tema que possui implicações filosóficas e religiosas, configurando um conjunto de complexidades no que diz respeito ao seu ensino, sobretudo à sua aprendizagem. Nesse sentido, as orientações educacionais complementares aos parâmetros curriculares nacionais ( $\mathrm{PCN}+$ ) do Ensino Médio (BRASIL, 2002) apresentam importante reflexão sobre o ensino da temática origem e evolução da vida: trata-se de um dos temas mais instigantes, complexo e abstrato para o ser humano, que tem buscado compreender as origens da vida, da Terra, do Universo e dele próprio. Esses conteúdos têm grande significado científico e filosófico, pois abrangem questões polêmicas, envolvendo várias interpretações sobre a história da vida. Além da complexidade da construção de conceitos científicos, a polêmica temática "Origem da Vida" requer uma atenção extra do professor na sua abordagem, devido aos conflitos existenciais e religiosos envolvidos. Podemos perceber a grande influência cultural nessa temática, conforme o diálogo entre os pesquisadores e o Estudante 31:

Pesquisador (P): Agora, vamos conversar sobre a atividade relacionada à origem da vida. Nos dois momentos, antes e depois do processo de ensino, tens uma visão criacionista. Como chegaste nessas opiniões?

Estudante (E): Ah tipo... antes eu não sabia que... não tinha esses dados... que tinha panspermia esses negócio aí... e tipo por causa da religião mesmo que dai a gente acredita. Dai assim né... a gente estudou mais, só que continua o mesmo. Dai tipo da evolução química que eu achei que também podia ser... dai que a gente é composto por célula e um monte de coisa né... ai podia ser também.

P: Então tu possuis dúvidas quanto a evolução química, mas acreditas no criacionismo devido a tua religião?

E: É.

P: É o que tu aprendeste com os teus familiares?

E: Abam. É tipo... que nem a minha mãe... tipo falava assim... só que ela nunca obrigou tipo ab você é isso daqui e quando perguntado tem que ser isso daqui, porque isso daqui é o que eu sou e tem que ser igual. E ela sempre deixon eu escolher o que en queria ser... tipo se en queria continuar na mesma religião que ela e tal. Ai tipo... é o que en gosto, o que en acredito.

P: A evolução química não traz nenbuma dúvida, estás seguro quanto ao criacionismo?

E: Tipo... eu acredito, mas se... fosse assim, tipo assim... sei lá daqui a uns anos falarem ah não sei o que da evolução química talvez eu poderia mudar, mas por enquanto eu tô segura.

P: Ok, a evolução química é como se fosse um plano B, no futuro talvez.possas ver de forma diferente, mas no momento acreditas no criacionismo, é isso?

E: É, aham.

P: Por que tu pensas que as outras hipóteses podem ser verdadeiras?

E: É porque... tipo... nem a do cristianismo foi certamente o que foi né... é meio 
estranho, mas pode ser... eu sei lá, tipo se em alguns anos descobrirem e tal... mas, por enquanto é a do criacionismo.

Nicolini (2006) enfatiza que o tema "origem da vida" trata-se de um tema central em diferentes religiões, aspecto que denota a grande complexidade do seu ensino no ambiente escolar. Destaca, ainda, que, em sala de aula, as ideias científicas são confrontadas com as crenças religiosas, que são interiorizadas culturalmente pelos estudantes. Ao encontro desse pensamento, Delizoicov, Angotti e Pernambuco (2002) ressaltam que os conceitos e explicações das Ciências Naturais, muitas vezes, contrariam as percepções de vivência social e cultural dos estudantes; sendo assim, o conhecimento científico tem grande impacto sobre as visões de mundo existentes, interagindo com interpretações religiosas, comportamentos e hábitos de tradição. Portanto, cabe ao professor entender o universo cultural do estudante, ou seja, sua tradição cultural, étnica e religiosa, meios de comunicação a que tem acesso, grupo de convívio, para, assim, criar estratégias mais adequadas, para o aprendizado do conhecimento científico.

Devido à complexidade da temática, muitos professores não coletam os conceitos espontâneos dos estudantes e, muitas vezes, acabam não ensinando a origem da vida, em sala de aula. Contudo, os conceitos espontâneos dos estudantes se transformam em um importante referencial para o ensino de tema, no processo de construção do conhecimento científico. Schroeder (2008) destaca que os conceitos espontâneos são carregados de diversas determinantes, sensoriais, emocionais, afetivas e morais, visto que são construídos nas relações mediadas pelos familiares, grupos de amizade ou por outros grupos específicos, como, por exemplo, a comunidade religiosa. Os conceitos espontâneos configuram-se como o resultado de conjuntos de representações com universo simbólico característico, formados por meio de sistemas de interpretação da realidade, ou seja, visões de mundo. Talvez, devido a essa carga afetiva, os estudantes tenham dificuldades em compreender outra possibilidade explicativa a respeito de um tema, fato que dificulta a construção de um conhecimento trabalhado em sala de aula.

Nesse sentido, Vygotsky (2001) ressalta que o afeto influencia diretamente: no desenvolvimento do cognitivo dos indivíduos, no ato de pensar, a motivação, a necessidade, os interesses, dentre outros sentimentos que movimentam e direcionam o pensamento. Do mesmo modo, o pensamento influencia, também, na parte afetiva e volitiva do ser humano, isto é, no seu comportamento. As emoções estão relacionadas ao desenvolvimento das funções psicológicas superiores, ao pensamento conceitual. Vygotsky (1998b) defende que para compreender a fala do outro, faz-se necessária à compreensão do pensamento, visto que somente com as palavras torna-se impossível. Todavia, além do pensamento, o conhecimento da motivação do indivíduo é de suma importância para o entendimento do mesmo. Possivelmente, por não se sentirem motivados em aprender os conceitos científicos relacionados à temática e, bem como, não possuírem elos afetivos pelo conhecimento científico, visto que os seus conceitos espontâneos diferem fortemente desses, os estudantes possuem dificuldades em internalizar os conceitos sobre o tema "origem da vida", ou, em algumas vezes, não internalizam, ou seja, não há um processo de construção do conhecimento.

Alguns estudantes, apesar de permanecerem com seus conceitos espontâneos, apresentam, em seu discurso, elementos do conhecimento científico. A hipótese da evolução química, que explica a origem da vida, foi identificada nos dizeres de alguns estudantes, antes e depois do processo de ensino, conforme nos mostra o exemplo comparativo a seguir: 
Grimes, C.; Schroeder, E.

Conceitos de um estudante relacionados à origem da vida, antes do processo de ensino

- Nível de Desenvolvimento Potencial:

A vida se originou da evolução química, na união de compostos do planeta, para muitos um ser superior criou, mas não bá provas para isso. [Estudante 40]

Após o processo de ensino - Nível de Desenvolvimento Real:

Na minha opinião, a vida surgiu da evolução química, a vida é muito complexa para ser de um ser superior, a evolução química é a mais evidenciada, criacionismo foi um mito criado na cabeça das pessoas. [Estudante 40] [atividade de construção e de complemento]

Percebemos que os conceitos apresentados após as aulas de Biologia se mostraram mais consistentes, do ponto de vista científico, além de os estudantes aparentarem maior confiança em seu discurso, em comparação com os seus conceitos originais. Possivelmente, isto decorreu como resultado dos processos interativos que aconteceram nas aulas. Ao encontro desse pensamento, Vygotsky (1998a) ressalta que o aprendizado desperta vários processos internos de desenvolvimento nos estudantes; no entanto, esses processos são operados somente quando os estudantes interagem com os indivíduos em seu ambiente, e quando em cooperação com os seus colegas. Quando internalizados, esses processos passam a fazer parte das aquisições do desenvolvimento independente do estudante.

Outro estágio de pensamento conceitual identificado foi "Estudantes que atribuem a origem da vida ao criacionismo, mas ainda possuem dúvidas". Ao final do processo de ensino, alguns estudantes apresentaram dúvidas sobre seus conceitos, coletados antes do processo de ensino. Apresentamos, a seguir, um exemplo comparativo:

Conceitos de um estudante relacionados à origem da vida, antes do processo de ensino

- Nível de Desenvolvimento Potencial:

Pra mim a vida surgiu através da criação divina... [Estudante 2]

Após o processo de ensino - Nível de Desenvolvimento Real:

Pra mim a vida veio através de um ser chamado Deus, mas depois de conhecer as outras teorias fiquei em dúvida sobre a origem da vida no universo. [Estudante 2] [atividade de construção e de complemento]

A construção de conceitos é um processo complexo e dinâmico. Nesse processo, ocorre a transformação do pensamento mais elementar, pensamento sincrético ou por complexos, para o pensamento mais abstrato, o pensamento conceitual propriamente dito. Cada indivíduo constrói conceito de maneira diferente, condicionado por aspectos de ordem biológica e sociocultural. Desse modo, as dúvidas, os conceitos fragmentados e desconexos podem acontecer no discurso dos estudantes. O processo de construção de conceitos não é linear e mecânico; apesar de aprender os conceitos científicos, o estudante pode continuar, temporariamente ou 
definitivamente, com os seus conceitos espontâneos, apresentando o pensamento por complexos, variando de acordo com a sua idade. As dúvidas conceituais apresentadas nos dizeres dos estudantes podem estar relacionadas ao pensamento por complexo. Nesse sentido, Vygotsky (2001) destaca que, na adolescência, a transição entre o pensamento primitivo e conceitual é o pensamento por complexo. Aprofundando esse pensamento, Vygotsky (1998b) argumenta que, na adolescência, as formas primitivas de pensamento, o sincrético e por complexos, aos poucos, vão dando lugar ao pensamento conceitual. Contudo, o adolescente ainda utiliza as formas mais elementares de pensar, pois essas ainda encontram-se presentes em diversos campos do seu pensamento. O pensamento por complexo não é utilizado somente pelas crianças; os adultos, no dia a dia, também podem recorrer a formas de pensar que se assemelham aos complexos. Desse modo, o papel fundamental do pensamento por complexo é constituir elos de ligações e formar relações, à medida que começa a organizar as impressões desordenadas e desenvolve embasamento para generalizações futuras. Podemos perceber, no diálogo entre os pesquisadores e o Estudante 2, o pensamento por complexo presente no discurso deste:
P: As aulas te ajudaram a mudar alguma ideia sobre origem da vida?
E: Sim, alguma... porque en fiquei assim... agora entre aquela lá da célula, que a gente pode ter surgido, da evolução química.
P: Tu ficaste em dívida entre essa e outra?
E: E a do criacionismo.
P: Ainda estás em dúvida ou já foi solucionada?
E: Não, mas pra mim ainda mais, na minha sugestão, foi um ser que veio e fer. tudo... e criou nós.
P: Então tu acreditas na criação divina e estas em dúvida com a evolução química?
E: Isso.
P: Isso está relacionado ao que tu viste durante a tua vida?
E: É eu acho que é.
$\mathrm{P}:$ Relacionado a questões religiosas?
E: Isso.
P: Como que tu chegaste nessa primeira opinião?
E: Desde pequena eu sube que a gente foi criado assim, aprendi assim.
P: Mas, por que ficaste em dúvida com a evolução química?
E: Porque eu acho que mais me chamou atenção como que a gente pode ter surgido, de uma célula a gente ter evoluído.
P: E como que tu chegaste na segunda opinião, da dúvida?
$\mathrm{E}:$ Na dúvida porque en não sabia das outras hipóteses né....
P: E tu aprendeste?
E: Eu aprendi... dai eu fiquei na dúvida.

Essa forma de pensamento mais primitiva, sincrética e por complexo, dificulta a compreensão do significado das palavras, das generalizações e da abstração dos conceitos, característicos do pensamento conceitual. De acordo com Vygotsky (1998b), um estudante, em um nível mais primitivo de desenvolvimento, no pensamento sincrético, é incapaz de compreender a generalidade, ou seja, o significado das palavras. Contudo, quando alcança o pensamento por 
generalizações, no nível mais elevado do seu desenvolvimento, o significado das palavras é compreendido pela lei de equivalência de conceitos, isto é, os conceitos podem ser transformados em outros conceitos de diversas maneiras.

A dificuldade de compreensão dos conceitos científicos e de generalização dos conceitos pode ser observada no diálogo entre os pesquisadores e o Estudante 32, demonstrando as dúvidas e confusões do último:

\section{P: Achaste difícil aprender essas hipóteses cientificas? \\ E: Dificil não foi, mas pra mim como eu tenho mais conhecimento pelo criacionismo eu meio que estranbei assim. \\ P: Então tu estás segura sobre a tua opinião relacionada ao criacionismo? \\ E: Aham. \\ P: Apesar de estar segura, tens dúvidas, é isso? \\ $\mathrm{E}:$ Ai... porque é muita... diferença de antigamente pra hoje, teve mudanças. Nas reportagens di₹ uma... que eu vejo di uma coisa, ai tu chega na escola o professor fala que foi totalmente diferente, ai tu não sabe em qual tu vai acreditar... ai eu tenho bastante dúvida porque aí eu pergunto, eu vejo bastante reportagem essas coisas assim, as reportagem diz. uma coisa que os especialistas nisso diz. uma coisa, ai tu pergunta pro professor, totalmente diferente do que mostrou, e pelo que eu vejo no criacionismo tem mais a ver assim.}

As interações discursivas dialogadas e não dialogadas são fundamentais para o desenvolvimento de um pensamento por generalizações e para a construção dos conceitos científicos. De acordo com Schroeder (2008), na abordagem comunicativa não dialogada, o docente articula a sua fala e os estudantes somente ouvem, prevalecendo a visão científica; na abordagem comunicativa dialogada, ocorre a interação comunicativa, por meio de questionamentos e discussões entre professor/estudante e estudante/estudante, além de não deixar a visão científica de lado. O professor, como mediador dos processos cognitivos, tem importante papel no processo de construção do conhecimento. Contudo, as interações discursivas, em grande parte, eram não dialogadas, ou seja, somente o professor falava, sendo que não promovia a discussão dos conteúdos em sala de aula e não estimulava questionamentos dos estudantes. Esta falta de interações era direcionada propositalmente pelo docente, devido à polêmica temática. Desse modo, os processos de aprendizagem ficaram um pouco prejudicados em relação à generalização e construção de conceitos. Nesse sentido, Vygotsky (2001) destaca que o discurso do ambiente escolar (o científico), com significados definidos, determina o desenvolvimento das generalizações dos estudantes, o círculo de formações conceituais mais complexas.

A construção de conceitos científicos depende de outros fatores externos e internos, caracterizando um processo de extrema complexidade. Ao encontro desse pensamento, $\mathrm{Vy}-$ gotsky (1998b, p. 100-101) discute que: “[...] quando se examina o processo da formação de conceitos em toda a sua complexidade, este surge como um movimento do pensamento dentro da pirâmide de conceitos, constantemente oscilando entre duas direções, do particular para o geral e do geral para o particular".

O autor aborda, ainda, que o pensamento na adolescência é transitório; após a formação de conceitos, os adolescentes empregam o conceito em uma situação concreta com extrema 
facilidade, todavia, possuem dificuldades em aplicar esse conceito em palavras, resultando em uma denominação verbal restrita.

Apesar de ser uma base para o pensamento conceitual, o complexo possui uma configuração muito diferente do conceito. Para Vygotsky (2001, p. 220), o conceito pressupõe “a discriminação, a abstração e o isolamento de determinados elementos e, ainda, a habilidade de examinar esses elementos discriminados e abstraídos fora do vínculo concreto e factual em que são dados na experiência”. Conforme o autor, já o pensamento por complexo é impotente e possui abstrações fracas, possuindo um processo de discriminação de atributos, extremamente fraco. Entretanto, o pensamento conceitual realiza os processos de síntese e a análise, bem diferente do que vimos nesse estágio de pensamento conceitual, no qual as dúvidas e as confusões predominam, ou seja, o pensamento por complexo.

No terceiro estágio do pensamento conceitual, temos "Estudantes que transformaram os seus conceitos relacionados à origem da vida". Percebemos que os estudantes transformam os seus conceitos, mesmo quando o tema ensinado seja desafiador. Contudo, os caminhos percorridos pelos estudantes nos processos de aprender são diversos, e o desenvolvimento dos estudantes deve ser compreendido como um processo complexo que demanda numerosas etapas. Observamos que a maioria dos estudantes passou a utilizar elementos do conhecimento científico em seu discurso.

A evolução química, hipótese mais aceita pela ciência na atualidade para a explicação da origem da vida, esteve presente nos conceitos de alguns estudantes após o processo de ensino, se comparada com as hipóteses que possuíam antes do desenvolvimento das aulas sobre a temática. Alguns estudantes construíram o conhecimento sobre a origem da vida utilizando a hipótese da evolução química, e esses estudantes apontaram primeiramente, em seu discurso, a origem no criacionismo, conforme o exemplo a seguir:

Conceitos de um estudante relacionados à origem da vida, antes do processo de ensino

- Nível de Desenvolvimento Potencial:

Acredito que foi como criação Divina, sendo que um ser superior, no caso Deus, tenha criado o homem pelo pó e a mulher pelas costelas do mesmo. [Estudante 25]

Após o processo de ensino - Nível de Desenvolvimento Real:

Assim, minha resposta anterior foi baseada no cristianismo. Ainda não duvido de Deus, mas agora não penso tanto que ele criou e originon a vida. Acredito agora que foi pela teoria da Evolução Química, por ser tão comprovados os fatos que eles apresentam e terem uma explicação tão complexa para os mesmos. [Estudante 25] [atividade de construção e de complemento]

Apesar das transformações conceituais, os conceitos científicos construídos ainda apresentam muitas fragilidades conceituais. Essa fragilidade conceitual apresentada nos dizeres dos estudantes pode estar relacionada ao pensamento por complexo dos mesmos. Para Vygotsky (2001), o desenvolvimento de conceitos científicos, no ambiente escolar, trata-se de uma questão prática de grande importância, pois, nesse processo, ocorre o amadurecimento das funções psicológicas do estudante. Desse modo, no processo psicológico, ocorre um movimento 
de amadurecimento conceitual, ou seja, o processo se dá como resultante da relação dialética entre os conceitos espontâneos e os conceitos científicos - os espontâneos se transformam numa base para o desenvolvimento dos conceitos científicos. A relação dos estudantes com os conceitos científicos é diferente da relação com os conceitos espontâneos, pois os científicos se constituem no processo de aprendizagem escolar, e os espontâneos são decorrentes dos processos de experiência pessoal e cotidiana dos estudantes. As motivações internas que levam o estudante a formar conceitos científicos são distintas daquelas que levam a formação dos conceitos espontâneos. O Estudante 25, conforme o diálogo abaixo, construiu conceitos científicos relacionados à origem da vida, ou seja, transformou os conceitos espontâneos na sua estrutura, por meio dos científicos internalizados, na ZDP, como resultado dos processos de aprendizagem em sala de aula.

P: Agora, vamos conversar sobre a Atividade relacionada à origem da vida, na primeira parte indicaste que ocorreu devido ao criacionismo e na segunda parte, apontaste a evolução quimica. Como você chegou à primeira opinião?

E: Pelo fato que a gente tem em casa assim, de ir na igreja, dai acreditar que ele fer.tudo.

P: Na segunda, como chegaste?

E: Nas outras séries a gente não estudava essas coisas assim né, bem complexa. Daí agora teve essa noção dessas hipótese. Meu essa evolução química teve muito assim, tipo todos os fatos comprovados, essas coisas assim sabe? Tudo complexo, tem tudo a ver que nem, aquele negócio lá... que esses animais ali um vai originando o outro que o professor passou aquele vídeo pra gente, meu explica muito bem assim pelo que eu entendi sabe, dai que nem de Deus tu fica lá pensando como é que ele foi criar a primeira coisa então, dai dali tu tem desde a primeira coisa que veio.

P: Então, o vídeo foi esclarecedor?

E: Foi.

P: Tu estás segura sobre essa opinião sobre a evolução química?

E: Aham.

P: Ou possuis dúvidas ainda quanto ao criacionismo?

E: Não, tipo eu acredito em Deus, mas não na criação. Que querendo ou não se a gente acreditar tem que acreditar coisa né, mas pra mim a evolução tem bem mais coisa pra comprovar sabe do que de Deus, porque quem é que conbeceu Deus pra comprovar essas coisas? Ninguém né. E essas coisas qualquer lugar que tu vai tem essas coisas comprovando como surgiu.

Apesar da forma "neutra" como o professor apresentou as hipóteses científicas e não científicas sobre a origem da vida, do desenvolvimento de poucas interações discursivas, além dos aspectos afetivos relacionados à temática e a sua complexidade, há indicadores de que alguns estudantes construíram conceitos científicos, superando seus conceitos espontâneos. Em outra situação, talvez, mais estudantes pudessem desenvolver um pensamento conceitual mais elaborado.

O ensino de Biologia tem como função, gradativamente, introduzir os estudantes no universo conceitual mais elaborado que caracteriza o pensamento científico; no entanto, desta- 
camos, novamente, determinadas crenças podem dificultar este processo para a aprendizagem científica sobre a origem da vida. Por sua vez, conforme Oliveira (2011, p. 123), o ensino da origem da vida e da evolução biológica apresenta dificuldades referentes a complexidades conceituais e a aspectos culturais e religiosos, assim sendo, na educação científica surgem conflitos e tensões entre os conhecimentos científicos e as crenças.

Destacamos que, além do processo de desenvolvimento do pensamento conceitual, a complexidade da temática de estudo, envolvendo conflitos entre as crenças e o ensino e a aprendizagem do conhecimento científico, gerou dificuldades no processo de construção de conceitos. Desse modo, percebemos que a maior parte dos estudantes manteve formas de pensar mais elementares e que caracterizariam o pensamento por complexos. Contudo, enfatizamos que ocorreram evoluções conceituais, estudantes transformaram conceitos espontâneos em conceitos científicos, ou seja, desenvolveram o pensamento conceitual propriamente dito, saindo do plano concreto e fazendo relações mais abstratas.

Constatamos que os estudantes aprendem de maneira totalmente diferente, pois, no desenvolvimento das funções psicológicas superiores, os conceitos espontâneos atuam como uma base para a internalização dos conceitos científicos. Contudo, esse processo varia de estudante para estudante, visto que cada indivíduo possui suas vivências únicas, aspecto que confere, ao papel do professor que medeia o conhecimento científico, um complexo desafio. Ressaltamos que, no processo de ensino estudado, indicativos apontam que os 45 estudantes do primeiro ano do Ensino Médio não atingiram o mesmo nível de pensamento conceitual, assim como o nível de excelência em relação aos conceitos científicos sobre a origem da vida, no entanto, em níveis diferentes, aconteceram mudanças na forma de pensar dos estudantes.

\section{Considerações finais}

No processo de ensino, o professor tem função fundamental: na organização do ambiente de aprendizagem, no desenvolvimento das interações discursivas em sala de aula, na proposição de tarefas desafiantes e significativas aos estudantes, bem como a efetivação de processos que poderão gerar aprendizagem e o desenvolvimento dos seus estudantes ao aprenderem os conhecimentos científicos. Assim, o docente atua como mediador com vistas à internalização dos conhecimentos científicos e ao desenvolvimento das funções psicológicas superiores, visando à tomada de consciência dos indivíduos.

O processo de construção dos conceitos não se trata de um simples conjunto de conexões que ocorrem pela lógica transmissão-recepção, com o auxílio da memória. A construção conceitual exige que o pensamento do estudante se eleve aos níveis superiores de desenvolvimento. Desse ponto de vista psicológico, a aprendizagem conceitual trata-se de um ato de generalização, ou seja, um complexo processo psicológico, associado à linguagem. Um conceito não acontece sem a palavra, Vygotsky compreende a linguagem não apenas como um instrumento de comunicação, mas como organizador do pensamento.

Os conceitos científicos são construções culturais com significados específicos, e mantêm relações com os conceitos espontâneos dos estudantes. Nesse processo, o professor contribui para que os estudantes possam efetivar as conexões entre sua compreensão cotidiana e o conhecimento científico. Nesse sentido, destacamos que os conceitos científicos são cons- 
truídos em distintos níveis de diálogo, que acontecem pelas relações sociais de produção que são estabelecidas entre Professor e estudantes e entre os próprios estudantes. Os conceitos atuam na construção da subjetividade dos indivíduos, pois, na aprendizagem do conhecimento científico, os conceitos deixam de ser objetos estranhos aos estudantes e se tornam instrumentos do pensamento destes.

$\mathrm{Na}$ aprendizagem de conceitos científicos que podem gerar ideias conflituosas, a construção do pensamento conceitual se torna ainda mais complexa, pois, apesar da abordagem pedagógica do professor, o estudante, de forma consciente, pode não construir os conceitos científicos. Neste sentido, muitos conhecimentos da Biologia podem gerar conflitos éticos, morais e culturais, na sua aprendizagem, tais como: evolução biológica, aborto, células tronco, energia nuclear, sexualidade, clonagem, transgênicos, dentre outros. Desse modo, para o ensino desses conteúdos, necessita-se de maior dedicação e preparo docente.

No estudo do tema "Origem da Vida", identificamos as crenças dos estudantes, além de suas ideias conflituosas. Percebemos que o ensino e a aprendizagem da temática em sala de aula é complexa, visto que aspectos culturais, religiosos, existenciais e afetivos estão envolvidos na construção dos conceitos científicos. Contudo, ao aprender, o estudante utiliza a sua base conceitual - conceitos espontâneos e transforma-os ou supera-os na internalização dos conceitos científicos, modificando os espontâneos na sua estrutura. Com os conflitos, esse processo se torna um desafio. Para Vygotsky, a aprendizagem pode ser compreendida como processo de reestruturação/superação conceitual que ocorre a partir das interações entre os conceitos espontâneos e científicos. Vygotsky confere aos processos de ensino um importante papel para a aquisição/internalização dos conceitos científicos, neste sentido, a aprendizagem pode conduzir o estudante em direção a uma compreensão generalizada, condição importante para adentrar em níveis mais conscientizados dos próprios processos mentais ou, como diria Vygotsky, a consciência reflexiva chega ao estudante através dos portais dos conhecimentos científicos.

Apesar da influência das crenças, no decorrer do processo de ensino, percebemos que muitos estudantes conseguiram, satisfatoriamente, transformar seus conhecimentos relacionados ao tema "Origem da Vida". Foi possível perceber que o processo de construção de conceitos científicos acontece de forma diferente para cada estudante; contudo, podemos observar que alguns apresentaram concepções, especialmente após o processo de ensino, ancoradas em conceitos científicos já estudados. Assim, compreendemos que os estudantes estabeleceram associações conceituais e buscaram utilizar uma linguagem mais adequada à situação, ou seja, uma linguagem mais próxima da linguagem científica. Por outro lado, os conhecimentos derivados das ciências naturais devem estender as experiências dos estudantes na construção de compreensões adequadas sobre o meio natural e tecnológico em que vivem. Além disto, professores necessitam ser cautelosos frente às complexidades intrínsecas aos conhecimentos da ciência e sua aprendizagem, lembrando que são construídos de forma gradativa pelos estudantes, na medida em que vão desenvolvendo seu processo cognitivo.

\section{Agradecimentos}

Agradecemos à Coordenação de Aperfeiçoamento de Pessoal de Nível Superior (CAPES) pela concessão de bolsa de estudos a um dos autores. 


\section{Referências}

ANDRADE, J. J.; SMOLKA, A. L. B. A construção do conhecimento em diferentes perspectivas: contribuições de um diálogo entre Bachelard e Vigotski. Ciência \& Educação, Bauru, v. 15, n. 2, p. 245-268, 2009. Disponível em: <http://dx.doi.org/10.1590/S1516$73132009000200002>$. Acesso em: 27 ago. 2014.

BAUER, M. W.; GASKELL, G. Pesquisa qualitativa com texto, imagem e som: um manual prático. 7. ed. Petrópolis: Vozes, 2008.

BRASIL. Ministério da Educação. PCN+ ensino médio: orientações educacionais complementares aos parâmetros curriculares nacionais. Brasília, 2002.

CACHAPUZ, A. et al. (Org.). A necessária renovação do ensino das ciências. São Paulo: Cortez, 2005.

CERQUEIRA, A. V. Representações sociais de dois grupos de professores de biologia sobre o ensino de origem da vida e evolução biológica: aspirações, ambiguidades e demandas profissionais. 2009. 90 f. Dissertação (Mestrado em Educação em Ciências e Saúde) - Núcleo de Tecnologia Educacional para a Saúde, Universidade Federal do Rio de Janeiro, Rio de Janeiro, 2009.

DELIZOICOV, D.; ANGOTTT, J. A.; PERNAMBUCO, M. M. C. A. Ensino de ciências: fundamentos e métodos. São Paulo: Cortez, 2002.

GÓES, M. C. R. de. A abordagem microgenética da matriz histórico-cultural: uma perspectiva para o estudo da constituição da subjetividade. Cadernos Cedes, Campinas, v. 20, n. 50, p. 9-25, 2000. Disponível em: <http://dx.doi.org/10.1590/S010132622000000100002>. Acesso em: 27 ago. 2014.

GRIMES, C. A construção de conceitos científicos no estudo do tema “origem da vida”. 2013. 265 f. Dissertação (Mestrado em Educação) - Centro de Ciências da Educação, Universidade Regional de Blumenau, Blumenau, 2013.

NICOLINI, L. B. Origem da vida: como os licenciandos em ciências biológicas lidam com este tema? 2006. 97 f. Dissertação (Mestrado em Tecnologia Educacional nas Ciências da Saúde) - Núcleo de Tecnologia Educacional para a Saúde, Universidade Federal do Rio de Janeiro, Rio de Janeiro, 2006.

OLIVEIRA, M. C. A. Aspectos da pesquisa acadêmica brasileira sobre o ensino dos temas “origem da vida" e "evolução biológica”. 2011. 173 f. Dissertação (Mestrado em Educação Científica e Tecnológica) - Universidade Federal de Santa Catarina, Florianópolis, 2011.

OLIVEIRA, M. K. Vygotsky: aprendizado e desenvolvimento: um processo sócio-histórico. 4. ed. São Paulo: Scipione, 2002.

REGO, T. C. Vygotsky: uma perspectiva histórico-cultural da educação. 9. ed. Petrópolis: Vozes, 2000. 
Grimes, C.; Schroeder, E.

SANTOS, A. G. Conhecimento científico, crenças religiosas e a compreensão dos fenômenos da natureza no ensino médio. 2007. 223 f. Dissertação (Mestrado em Tecnologia Educacional nas Ciências da Saúde) - Núcleo de Tecnologia Educacional para a Saúde, Universidade Federal do Rio de Janeiro, Rio de Janeiro, 2007.

SCHROEDER, E. A teoria histórico-cultural do desenvolvimento como referencial para análise de um processo de ensino: a construção dos conceitos científicos em aulas de ciências no estudo de sexualidade humana. 2008. 388 f. Tese (Doutorado em Educação Científica e Tecnológica) - Universidade Federal de Santa Catarina, Florianópolis, 2008.

VERGARA, S. C. Métodos de pesquisa em administração. 2. ed. São Paulo: Atlas, 2006. VYGOTSKY, L. S. A construção do pensamento e da linguagem. São Paulo: Martins Fontes, 2001.

A formação social da mente: o desenvolvimento dos processos psicológicos superiores. 6. ed. São Paulo: Martins Fontes, 1998a.

Pensamento e linguagem. 2. ed. São Paulo: Martins Fontes, 1998b.

WERTSCH, J. V.; DEL RIO, P.; ALVAREZ, A. Estudos socioculturais da mente. Porto Alegre: Artmed, 1998.

Artigo recebido em 10/01/14. Aceito em 13/04/15. 